\title{
AT IAM SATIS EST DE REBUS GUARANICIS: LA DIGRESSIO ETNOGRÁFICA EN EL ANNUS PATIENS DE JOSÉ PERAMÁS
}

\author{
At iam satis est de rebus guaranicis: the ethnographic digressio in the Annus \\ Patiens of Joseph Peramás
}

\section{Resumen}

Marcela Alejandra Suárez*

Ciertos autores señalan que algunas fuentes del período jesuita pueden ser consideradas etnográficas. Pero las noticias relacionadas con la naturaleza y las poblaciones indígenas americanas no siempre aparecen como tema de una única obra. A menudo, suelen estar incorporadas en relatos de viajes, cartas o diarios.

En el Annus Patiens siue Ephemerides, el P. Peramás desplaza en tres ocasiones la narratio del viaje hacia el exilio para describir la Pampa (ff. 28-30), las actividades jesuíticas en la Provincia del Paraguay (ff. 49-53) y las misiones guaraníes (ff. 53-92). En este artículo analizaremos esta última digresión y su función en el texto a partir de las estrategias retóricas que el jesuita pone en juego.

$<$ Peramás $><$ Annus Patiens $><$ Digressio $><$ Etnografía $>$

\section{Abstract}

Some authors point out that some jesuit sources can be considered ethnographic. But the news related with the nature and the native populations not always appear as the theme of a single work. They are usually incorporated in tales of travel, letters or diaries.

In the Annus Patiens siue Ephemerides, Peramás displaces in three occasions the narration about the trip towards the exile to describe the Pampa (ff. 28-30), the jesuit activities in the province of Paraguay (ff. 49-53), and the missions of Guaranies (ff. 53-92). In this paper, we will analyze the rhetoric strategies of the last digression and we will determine their function.

$$
<\text { Peramás }><\text { Annus Patiens }><\text { Digressio }><\text { Ethnography }>
$$

Recibido: 01/12/2016//Aceptado: 20/02/2017

\footnotetext{
* Doctora en Letras, Profesora Titular Regular. Facultad de Filosofía y Letras. Universidad de Buenos Aires. CONICET. m.suarez61.ms@gmail.com
} 
Suárez. At iam satis est de rebus guaranicis: la digressio etnográfica en el Annus Patiens de José Peramás.

Numerosos son los autores que destacan que para la Compañía de Jesús la escritura forma parte de su labor pastoral ${ }^{1}$. La importancia que los jesuitas le otorgan a la tarea de escribir se traduce en una enorme cantidad de cartas, crónicas, historias y diarios de viajes en los que dan cuenta de las actividades realizadas, describen los lugares en los que se han asentado y los pueblos con los que han mantenido contacto.

Al referirse a la bibliografía jesuítica, Asúa (2003) señala que entre 1600 y 1773 los hijos de Loyola escriben más de 4000 obras de carácter científico. En efecto, el saber al que se han dedicado los jesuitas con más asiduidad ha sido la historia natural en sentido amplio, es decir, abarcando la geografía, la cartografía, la astronomía, la botánica y la zoología (cf. Pino Díaz, 2008). Asimismo, ciertos autores señalan que algunas fuentes del período jesuita pueden ser consideradas etnográficas. Pero las noticias relacionadas con la naturaleza y las poblaciones indígenas americanas no siempre aparecen como tema de una única obra². A menudo, suelen estar incorporadas en relatos de viajes, cartas o diarios.

Entre los testimonios americanos más destacados cabe mencionar el diario del P. José Manuel Peramás de la provincia jesuítica del Paraguay, donde queda plasmada la experiencia del exilio a partir de dos versiones: la primera en español (Narración de lo sucedido a los jesuitas del Paraguai desde el día de su arresto hasta Faenza en Italia en carta de 24 de diciembre 1768, escrita en Turín a un Señor Abate de la ciudad de Florencia) ${ }^{3}$ y la segunda en latín (Annus patiens siue Ephemerides quibus continetur iter annum Iesuitarum Paraquariorum Cordubae Tucumaniae profectorum $)^{4}$. La Narración es la versión más difundida y consultada por los historiadores a partir de la publicación llevada a cabo por el P. Furlong (1952) y la reedición de Lila Perrén de Velasco (2004). Sin embargo, la versión latina, inédita y prácticamente desconocida para el mundo académico, presenta respecto de la primera notables diferencias que deben ser tenidas en cuenta a la hora de abordar estos textos. Entre dichas diferencias analizaremos la digresión dedicada a las misiones guaraníes (ff. 53-92) y su función en el texto a partir de las estrategias retóricas que el jesuita pone en juego ${ }^{5}$.

José Peramás, de origen catalán, nace el 17 de marzo de 1732. Después de haber ingresado en la Compañía de Jesús, es enviado a tierras americanas en 1755. A fines de ese mismo año, llega a Córdoba del Tucumán. Trabaja un tiempo en la reducción de San Ignacio Miní y en ese mismo período se le encarga la redacción de las Cartas Anuas de la Provincia del Paraguay. Al cabo de tres años debe abandonar sus tareas apostólicas y regresar a Córdoba donde se hace cargo de la cátedra de Retórica y Teología Moral. Acepta la carga con el espíritu de siempre y se entrega en cuerpo y alma a la enseñanza. Pero su laboriosa y pacífica vida es interrumpida en 1767 cuando el rey de España, Carlos

1 Diferentes autores señalan la importancia que tiene la escritura para la Compañía de Jesús. Cf. Cardozo (1959), Morales (2005), Domingues (2006).

2 Entre las obras que se caracterizan por abordar estos temas de manera única se destacan Descripción corográfica del Gran Chaco Gualamba (Pedro Lozano, 1733), Descripción de la Patagonia (Tomás Falkner, 1774), Historia de los Abipones (Martín Dobrizhoffer, 1784).

3 El autógrafo se conserva en la Biblioteca del Colegio de la Cartuja (Granada).

4 El autógrafo se encuentra en el Archivo General de la Compañía de Jesús (Roma).

${ }_{5}$ Con respecto al uso de la etnografía retórica para representar la alteridad, cf. Urdapilleta Muñoz (2015). 
III, da la orden de expulsar a los jesuitas de los territorios americanos. Así comienza el largo camino hacia el destierro: diez días encerrados en el refectorio, veintisiete días de viaje en carretas hasta la ensenada de Barragán, casi cuatro meses de navegación hasta llegar a Cádiz y luego el traslado hacia los Estados Pontificios 6 .

En el Annus Patiens el relato del viaje hacia el exilio comienza el 12 de julio (Mense Iulio die XII). Peramás detalla días, meses y horas, por cuanto la redacción resulta contemporánea al acontecer ${ }^{7}$. Sin embargo, la narratio es interrumpida en tres ocasiones para describir la Pampa (ff. 28-30), las actividades jesuíticas en la Provincia

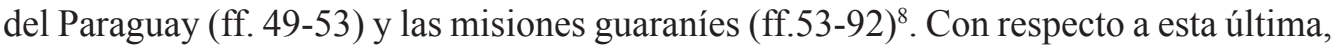
el propio Peramás, antes de retomar la narración sobre la navegación (continuatio nauigationis), así se expresa:

At iam satis est de rebus guaranicis. Vos Guaraniorum amanti facile digressionem istam, nimiam fortasse condonabitis.

Sobre los asuntos de los guaraníes, ya es suficiente. Vosotros transmitiréis esta digresión, quizá excesiva, al que sin duda sienta afecto por los guaraníes.

Desde el punto de vista retórico la digressio es una auersio, es decir, una figura que implica el apartamiento o separación del objeto del discurso9. Esto significa que el tema tratado se abandona por un momento con el fin de incluir explicaciones, episodios o aspectos destinados a enriquecer y profundizar el tema principal. Respecto de la extensión, la preceptiva insiste en que no debe prolongarse en extremo para no desequilibrar la unidad del discurso.

Dentro del amplio abanico de posibilidades que adopta la digresión ${ }^{10}$, se destaca la digresión etnográfica que puede presentarse bajo la forma de los distintos tipos de euidentia o hipotiposis, esto es, bajo la forma de una descripción. La retórica clásica se vale de distintos términos (euidentia, descriptio, illustratio, demonstratio), para hacer referencia al hecho de describir pero todos ellos se vinculan con la posibilidad de "poner ante los ojos", de "hacer ver" por medio de palabras los rasgos característicos de lo que se quiere mostrar. La virtud de la descriptio, que es una figura de pensamiento por amplificación o adición, se funda sobre tres pilares planities et praesentia uel significantia ${ }^{11}$.

${ }^{6}$ Cf. Sommervogel (s.u. Peramás); Furlong (1952).

7 Mense Iulio die XIII; Augustus die I.

8 La historia de las nuevas poblaciones, sus creencias, costumbres y naturaleza despertaba una enorme curiosidad en el público europeo. Al respecto, Arbo-Laird (2015: 7) afirman: "The missions to the Guarani Indians in Paraguay are among the Society of Jesus' most famous endeavours in colonial Spanish America".

9 Cf. Quint. Inst. 4.3.14; Lausberg (1966: §848).

${ }^{10}$ La digressio es uno de los componentes retóricos más habituales de la literatura antigua y, sobre todo, de la prosa historiográfica.

${ }^{11}$ Cf. Prisc. Praeex. 10; Quint. 9.2.40; Her. 4.68. 
Según la Rhetorica ad Herenium (4.68), la descripción consiste en narrar algo de manera tal que parezca que los acontecimientos se representan y desarrollan ante nuestros propios ojos (Demonstratio est, cum ita uerbis res exprimitur, ut geri negotium et res ante oculos ese uideatur). Prisciano (Praeex.10) afirma que la descriptio es un discurso colligens et praesentans oculis quod demonstrat.

En el diario del catalán la digressio o descripción etnográfica está anticipada por la inclusión de un pasaje del Praedium Rusticum de Jacques Vanière ${ }^{12}$, a quien se le adjudica el temprano renombre de la comunidad guaraní. En efecto, el jesuita francés desarrolla en el final del L.XIV de su poema, una suerte de best seller del siglo XVIII, la digressio paraquarensi populo con miras a ensalzar a los cristianos de las Misiones del Paraguay que, habiendo sido feroces salvajes, se transformaron en un modelo de piedad cristiana y un ejemplo admirable de gobierno político. Aprovechando el prestigio y la credibilidad de los que goza el poeta, Peramás recurre pues al argumento de autoridad ${ }^{13}$ (argumentum ad uerecundiam) para luego dar paso a su discurso personal. En efecto, la poesía del jesuita francés desvirtúa la realidad, por lo cual el jesuita catalán produce su propia versión sobre los guaraníes en consonancia con la recomendación de Ignacio de Loyola de escribir informes de actividades que incluyeran descripciones de los lugares y pueblos visitados. El objetivo de Peramás es aportar una descripción etnográfica detallada y refutar algunas de las inexactitudes del texto francés. Por cuestiones de espacio solo nos detendremos en algunos pasajes.

Veamos el comienzo de la digresión:

Sed cum ego diu inter Guaranios fuerim et testis sim eorum quae cecinit Vanierius, operae pretium fore duxi, si illius uersibus aliqua addidissem, non quod omnia quae dici possunt de guaranicis rebus uelim dicere, opus enim erat ad ea integrum volumen, sed ut quae strictim ille posuit, ego latius explicem. Ergo diuisis membratim carminibus breuem explicationem subiiciam.

Pero como yo estuve durante mucho tiempo entre los guaraníes y fui testigo de lo que Vanière celebró, consideré que valdría la pena si agregaba a sus versos algunos detalles no porque quisiera decir acerca de los asuntos guaraníes todo lo que puede decirse, en efecto para esto sería necesario un volumen entero, sino porque lo que él expuso brevemente, yo lo desarrollaría ampliamente. Por lo tanto, tras dividir el poema en grupos de versos añadiré una breve explicación.

12 Jacques Vanière (1664-1739). Jesuita, poeta y latinista nacido en Causses. Se lo conoce como el Virgilio francés por su poema geórgico Praedium rusticum publicado de manera completa (16 libros) en Toulouse en 1730 .

${ }^{13} \mathrm{Al}$ referirse a las autoridades, Perelman- Olbrechts (1989: 472) afirman: "Las autoridades invocadas son muy variables: ora será "la opinión unánime" o "la opinión común", ora ciertas categorías de hombres, "los científicos", "los filósofos", "los Padres de la Iglesia", "los profetas"; a veces, la autoridad será impersonal: "la física", "la doctrina", "la religión", "la Biblia"; otras, se tratará de autoridades designadas por su nombre. 
En general, el comienzo de toda digressio etnográfica se caracteriza por una serie de tópicos tales como la brevedad, la exactitud, el conocimiento cabal y el tratamiento de un tema desarrollado muy superficialmente o poco difundido por los autores. El jesuita reelabora dichos tópicos y deja constancia de cuatro puntos fundamentales:

1) su punto de vista en tanto testigo ocular

2) la posibilidad de ofrecer mayor información y más detallada

3) la imposibilidad de abordar el tema de manera completa, lo cual implicaría producir un volumen sobre esta temática

4) su método de trabajo que consiste en comentar el extenso pasaje del Praedium Rusticum por grupos de versos

Con respecto al contenido, conviene señalar que el discurso etnográfico a menudo contempla cinco unidades fundamentales, aunque con frecuencia sin un orden específico: geografía (situs), características de los habitantes, clima, economía, organización sociopolítica, militar y religiosa. En virtud de la extensión del relato de Peramás, que abarca los ff.53 a 92, solo abordaremos tres de los cinco aspectos mencionados: geografía (situs), economía y organización política.

A propósito de la geografía o situs, Vanière escribe:

Et ueteris ne uana putes praeconia famae, nunc etiam mare trans altum iacet angulus orbis, quem qui norit apum credat me nomine gentis illius ingenium et uarios celebrasse labores.

Y que no se consideren vanos los elogios de la antigua fama, ahora incluso más allá de alta mar existe un rincón del orbe, que si alguien conociera, creería que yo he celebrado el talento de aquel pueblo y sus diversos trabajos bajo el nombre de abejas.

Peramás pone en duda la competencia de Vanière y refuta sus versos apelando a la técnica de la objeción:

Vellem explicuisset hic Vanierius (neque id poetam dedecebat) Guaraniorum fines paulo latius clariusque, nimis enim ieiune illud et confuse: nunc etiam mare trans altum iacet angulus orbis, cum infiniti sin trans mare orbis anguli; inter quos frustra, nisi expressiores fines posueris, guaranicam gentem quaesieris.

Hubiera querido que en este punto Vanière (y esto le era conveniente al poeta) desarrollara los límites de los guaraníes un poco más amplia y claramente; en efecto, el verso "ahora incluso más allá de alta mar existe un rincón del orbe", es demasiado escueto y confuso, puesto que más allá del mar 
los rincones apartados del orbe son infinitos, entre los cuales en vano se podría encontrar al pueblo guaraní a no ser que se hubiesen indicado límites más tangibles.

La escueta y confusa (ieiune et confuse) definición de Vanière le da pie a Peramás para ofrecer un desarrollo totalmente opuesto (latius et clarius). Con el fin de destacar aún más las deficiencias del poeta francés, el jesuita catalán apela al recurso intertextual de la cita, incorporando un pasaje de las Geórgicas de Virgilio:

Nam qua Pellaci gens fortunata Canopi accolit effuso stagnantem flumine Nilum et circum pictis uehitur sua rura phaselis quaque pharetratae uicinia Persidis urget, et uiridem Aegyptum nigra fecundat harena et diuersa ruens septem discurrit in ora usque coloratis amnis deuexus ab Indis, omnis in hac certam regio iacit arte salutem. (G. 4. 287-294)

Pues por donde el pueblo afortunado de la Cánope egipcia habita el lacunoso Nilo, tras el desborde del río, y es llevado alrededor de sus campos en pintadas canoas, y por donde apremian los pueblos vecinos de Persia, la del carcaj, y el río fecunda al verdegueante Egipto con negro limo y precipitándose corre por siete bocas diferentes, en su descenso de los tostados indos, toda la región funda en esta arte su salvación.

La cita virgiliana respalda el planteo de Peramás respecto de los límites, sobre todo si se tiene en cuenta que, de acuerdo con los requerimientos de la tradición etnográfica, Virgilio define el situs de Egipto en relación con sus límites: Cánope al oeste, Persia al este y la India al sur.

El jesuita catalán considera que si Vanière imita a Virgilio en la descripción de las abejas, bien podría haberlo imitado en la descripción de los límites, evitando de este modo la oscuridad del pasaje (Quanto satius Vanierius ipse, cum Guaranios apibus comparat canentem de apibus Virgilium, notioribus de Guarania positis finibus imitatus fuisset? $)^{14}$. A continuación, entonces, aporta su descripción:

Igitur describam ego breuiter Guaraniorum fines. Hi illi sunt. $\mathrm{Ab}$ oriente intactae duo siluae ad Paranae amnis fontes. $\mathrm{Ab}$ occasu solis Parana ipse qui urbem fluentinam et subiecta loca praeterfluit. Ad meridiem montes quos Tapes uocant, Brasilico litori inminentes. Ad septentriones flumen Tebiquari quod Paraquariorum agros et Guaraniorum diuidit. Oppida autem

\footnotetext{
${ }^{14}$ El propio Vanière, cuando compara a los guaraníes con las abejas, imita a Virgilio que escribe acerca de ellas, ¿cuánto mejor si lo hubiese imitado una vez establecidos los limites más conocidos de la región guaraní?
} 
posita sunt ut supra diximus ad ripas Paranae et Uruguaii praeter XIV illa, quae inter hos omnes sunt et bina illa quae sunt in Taruma supra uillam ditem longe ab urbe Assumptionis. Sed habitabant latius olim Guaranii ad Guayram et ad montes Tapes, et litus brasilicum: ibique a Iesuitis in oppida primum coacti sunt. Sed inde expulsi maleficiis Paulaniorum qui omnia circum uastabant captosque oppidanos in Brasiliam ad eruenda metalla abducebant in ea loca quae nunc incolunt descenderunt.

Por lo tanto, describiré brevemente los límites de los guaraníes. Estos son los siguientes: Al este dos selvas vírgenes junto a la cuenca del río Paraná. Al oeste, el propio Paraná que baña la ciudad de Corrientes y lugares vecinos. Al sur, las sierras llamadas Tapé, que amenazan a la orilla brasileña. Al norte el río Tebicuary que divide los campos de los paraguayos y guaraníes. Las reducciones están ubicadas, como dijimos más arriba, junto a la ribera del Paraná y del Uruguay excepto las 14 que están entre estos y las dos que están en Taruma, más allá de la Villa Rica, lejos de la ciudad de Asunción. Pero los guaraníes habitaban en otro tiempo extensiones más amplias junto al Guayra, los montes Tapé y el litoral brasileño y allí primero fueron reunidos por los jesuitas en reducciones. Sin embargo, expulsados de allí por las malas acciones de los paulistas que devastaban todo a su alrededor y conducían a los ciudadanos cautivos a Brasilia para extraer metales, descendieron a estos lugares que ahora habitan.

Peramás que insiste en reiteradas ocasiones en la brevedad de sus descripciones, lo cual no se condice con la longitud real de las mismas, se vale de un sistema de orientación integrado por puntos cardinales, ríos, montes y selvas para establecer los límites de la región de una manera detallada, clara y precisa. Además, tal como señala en el comienzo de su digressio, agrega detalles (addidissem) y desarrolla (latius) algunos otros aspectos: la ubicación de las reducciones y la referencia a la ubicación previa al conflicto con los paulistas.

La descripción y elogio que aporta el jesuita francés respecto de cómo viven los pueblos guaraníes supone el concepto de comunidad de bienes. Por tal razón, afirma en el pasaje que sigue:

Non certis armenta notis, non limite signant arua, sed in medium quaerentes omnia, fruges horrea conuectant in publica.

No marcan el ganado con señales precisas, no señalizan los campos con mojones, sino que procurando una distribución 
equitativa, llevan la cosecha a los graneros públicos.

Peramás toma este grupo de versos y aplica la técnica de la concesión (Illud de armentis uerum est et fuit tum maxime cum poeta scripsit) ${ }^{15}$, aceptando la afirmación del francés en virtud de que en otro tiempo hubo infiniti boum et vaccarum greges. Sin embargo, en el pasaje siguiente refuta la versión de Vanière en relación con los campos, remarcando que solo puede ser entendida en términos de poetica licentia:

Sed quae addit Vanierius: non limite signant arua, sed in medium quaerentes omnia, fruges horrea conuectant in publica, id poetica licentia dictum est.

Pero lo que Vanière agrega: "no señalizan los campos con mojones, sino que procurando una distribución equitativa, llevan la cosecha a los graneros públicos" es una licencia poética.

A partir de aquí, el catalán aborda entonces el tema de la propiedad pública y privada y presenta su propia descripción, en la que destaca que a cada familia se le asigna una parcela de tierra para que cultive. Los productos de esta siembra son propiedad particular de los colonos. Junto a los sembradíos particulares se encuentran los campos comunes y lo que estos producen se almacena en depósitos y constituye el fondo público:

Non enim arua omnia communia sunt, sed alia communia, unde fruges conuectantur in horrea publica; alia priuata unde domum quisque suam messes refert.

En efecto no todos los campos son comunes, sino que unos son comunes y la cosecha es transportada a los graneros públicos; otros son privados y cada uno lleva las mieses a su casa.

Toda la organización de la vida productiva de las reducciones se realiza en función de dos conceptos: abambaé (propiedad individual privada) y tumpabaé (propiedad colectiva o tierra de Dios). El abambaé comprende el lote agrícola, es decir, la parcela de tierra que es cedida a cada familia. El padre de familia siembra para los suyos trigo, raíces comestibles como la mandioca y la batata, algodón y otros frutos (ibi pro suo quisque studio frumenta serebant, panicum, gosipium, mandiocam quod genus est radicis satiuae, unde farinam et panem conficiunt et multum amant; batatas item quae genus aliud radicis sunt gratissimi saporis, melones, etc. ${ }^{16}$.La cosecha obtenida es propiedad exclusiva de la familia poseedora del lote. El tupambaé abarca tierras que pertenecen a la comunidad. Los productos y beneficios del régimen del tupambaé

\footnotetext{
${ }^{15}$ Lo del ganado es verdad y lo fue, sobre todo, cuando el poeta lo escribió.

${ }^{16}$ Allí por su parte cada uno sembraba trigo, mijo, algodón, mandioca que es un tipo de raíz cultivada, de la cual hacen harina y pan y les gusta mucho; asimismo, batatas que es otra raíz de muy rico sabor, melones, etc.
} 
permiten la manutención de los sacerdotes y la cobertura de las necesidades de la comunidad, especialmente en épocas de carestía y epidemias. A esto se refiere Peramás cuando escribe: igitur communis ager communiter aruatur, seritur, metitur; ex eoque senes, uidua, pupilli, pueri, puellaeque aluntur, his enim publice uictus et uestis datur ${ }^{17}$.

En relación con la organización política, leemos en el texto de Vanière:

Consilio non iure senes dominantur: $a b$ annis

una potestatem facit experientia rerum

unaque lex est iuris amans sua cuique uoluntas

En el consejo los ancianos no dominan por derecho: por efecto de los años la sola experiencia de las cosas forja la autoridad y la única ley es la voluntad de justicia que es afecta a dar lo suyo a cada uno.

Sobre este grupo de versos, Peramás comenta: Si Vanierius publicam hic excludit iurisdictionem et paternam senilemue solum oeconomiam ponit, falsus est et fallit ${ }^{18}$. Está claro que el error de Vanière (falsus est et fallit) queda supeditado a una prótasis condicional (si...excludit...). En este sentido, conviene recordar que la presencia del modo indicativo nos habla de un período real, lo cual significa que el error mencionado en la apódosis existe y, por lo tanto, el catalán lo refuta completamente a partir de su propia descripción:

Erant ibi publici magistratus regia auctoritate constituti. Quippe Kalendis Ianuarii praetor et minores magistratus et senatores eligebantur; electorumque nomina Bona Auras mittebantur, ut Regius Praetor qui ius Guaraniis dicebat, designatum praetorem et caeteros confirmaret. Confirmati publicam curam oppidi gerebant. Sed ne errarent, ut ferme parum Indi iudicio ualent, nihil grauius inconsulto Missionario statuebant.

Había allí magistrados públicos establecidos por la autoridad real, puesto que el 1 de enero se elegían el pretor, los magistrados menores y los senadores. Los nombres de los elegidos eran enviados a Buenos Aires para que el gobernador, que administraba justicia a los guaraníes, confirmara al pretor designado y a los restantes funcionarios. Una vez confirmados, llevaban adelante la administración pública de la ciudad. Pero para no errar, en vista de que comúnmente los indios poco prevalecen por su decisión, establecían que nada era más grave

\footnotetext{
${ }^{17}$ Por lo tanto el campo común se cultiva, se siembra, se mide comunitariamente; de allí son alimentados los ancianos, las viudas, los pupilos, los niños y niñas; en efecto, a estos generalmente se les da el alimento y la vestimenta.

${ }^{18}$ Si Vanière excluye aquí la jurisdicción pública y expone únicamente el orden paterno o senil, se equivocó y se equivoca.
} 
Suárez. At iam satis est de rebus guaranicis: la digressio etnográfica en el Annus Patiens de José Peramás.

que un misionero imprudente. ${ }^{19}$

Es de notar que tanto en esta digressio como más tarde en su obra De administratione Guaranica ${ }^{20}$ que retoma el sistema de legislación, la planificación urbana, la propiedad privada y pública, la educación y las artes, Peramás presenta a los guaraníes como ciudadanos activos y plenos de recursos ${ }^{21}$.

Según Marcus-Cushman (1982: 30-35), toda descripción etnográfica se caracteriza por una serie de convenciones literarias, entre las que cabe subrayar la presencia no invasiva del autor y el foco en situaciones de la vida diaria. En los pasajes citados es claro el empleo de la tercera persona del singular como marca de distanciamiento. Sin embargo, la presentación de detalles de la vida cotidiana resalta la sensación de intimidad del etnógrafo, afirmando la idea de que estuvo realmente allí, es decir, su condición de testis. Al referirse a las vestimentas de los indios, el catalán escribe:

Quod si amas scire, quaenam fuerint Indorum uestes, et quae domestica supellex, dicam id etiam saepissime enim uidi, cum aegrotorum confessiones et morientium auxilium ibam.

Si quieres saber cuál es la vestimenta de los indios y cuál el ajuar doméstico, te lo diré pues muy a menudo los vi cuando iba a confesar a los enfermos y a ayudar a los moribundos.

Y más adelante, cuando se detiene en la descripción de los lecti Indorum (hamacas) y en el método para combatir el frío que su uso provoca, afirma:

Cuius rei testis ipse sum: qui cum aegri confessionem quondam exciperem, subiectis prunis tunicam, nihil uidens, semiustulaui: [...]

De esta situación fui testigo yo mismo que, cuando alguna vez recibí la confesión del enfermo, me quemé la túnica con las brasas ubicadas debajo (de las hamacas), al no verlas.

Hartog (2002: 289) que concibe la forma de aprehender al otro como una "retórica de la alteridad", sostiene que "estas descripciones hacen ver un saber: en efecto, su punto focal es el ojo. Este las organiza (lo visible), delimita su proliferación y las controla (campo visual) y les da autenticidad (testigo). Por tanto, es él quien hace

${ }^{19}$ Es de notar que en el capítulo XXI de su obra De administratione guaranica comparata ad rempublicam Platonis commentarius, Peramás indica que los principales magistrados eran los siguientes: un corregidor, un teniente de corregidor, dos alcaldes urbanos, un tercer alcalde de hermandad para los asuntos rurales, cuatro regidores y un alguacil mayor, un procurador público y un escribano, y un alférez real.

${ }^{20}$ Cabe señalar que esta obra fue incluida en la colección de biografías titulada De vita et moribus tredecim virorum paraguaycorum (1793).

${ }^{21}$ Sin dudas, la digressio etnográfica del Annus Patiens, puede ser considerada el avant texte de De administratione guaranica. 
creer que se ve y se sabe, él es el productor de [...] la persuasión: yo lo vi, es la verdad". En este sentido, los jesuitas confían en la retórica del yo fui testigo ${ }^{22}$ que pasa a ser un nuevo criterio epistemológico de referencia sustituyendo de este modo a la autoridad de la palabra escrita transmitida.

El jesuita catalán subraya en todo momento que no solo ha estado entre los guaraníes sino que ha cumplido la función de sacerdote. En ambos casos, se presenta como testigo ocular. De ahí la relevancia del campo semántico del ver representado por la ocurrencia de los lexemas uideo, obseruo. Esto significa que describe a los guaraníes desde lo concreto y sensible ${ }^{23}$. La experiencia es su fuente de autoridad etnográfica, la cual le permite garantizar la verdad. Pero a la experiencia directa del "yo vi, yo fui testigo" es necesario sumarle el ser fiable. La importancia de la fiabilidad deviene uno de los dispositivos fundamentales para validar los relatos.

En esta línea, resulta indispensable entender el papel del autor-testigo mediante el concepto de ethos, término con el que se designa la imagen de sí que elabora el emisor en su discurso con la finalidad de influir en su posible receptor. ${ }^{24}$ El etnógrafo debe asumirse como un autor y al mismo tiempo como un testigo que no es neutro. Se acepta, entonces, que la descripción etnográfica habla tanto del objeto que se pretende representar como del propio autor o dicho de otro modo, es una representación mediada por el descriptor. Al respecto, Clifford Geertz (1989: 154) señala que "toda descripción etnográfica es interesadamente casera, es siempre descripción del descriptor y no del descrito." Un claro ejemplo de esta mediación se advierte en los pasajes relacionados con las artes. Al referirse a las artes rusticae, Peramás escribe: Harum quas numerat hic Vanierius agrestium artium plerasque docuerunt Indos ${ }^{25}$ Iesuitae $^{26}$. Y más adelante agrega: Sed praeter has artes rusticas callebant Guaranii urbanas artes omnes. Curarunt Iesuitae eo ex Hispanis urbibus magistros ire qui docerent. ${ }^{27}$ En ambos pasajes lo importante es destacar la imagen educadora de la Compañía con miras a cristalizar experiencias compartidas en una obra que, como tantas otras, estaba destinada a convertirse en un dispositivo memorístico y apologético. En este sentido, afirma Justo (2012: 45) "el modelo retórico- humanista tenía una articulación doble, por un lado, "yo vi y yo fui testigo", y por otro, la fiabilidad del testimonio otorgada por la Orden".

\section{Conclusión}

De acuerdo con nuestro análisis, en el Annus patiens Peramás construye la digressio etnográfica sobre los guaraníes apelando al argumento de autoridad representado por Vanière, cuyo texto refuta a partir de tres técnicas- objeción, concesión y refutación

${ }^{22}$ Cf. Padgen (1993: 51-88).

${ }^{23}$ La información de Peramás no proviene de sus lecturas sino de sus propias observaciones, de lo que ha visto personalmente. Su conocimiento es, sin dudas, testimonial.

${ }^{24}$ Cf. Amossy (2010).

${ }^{25}$ Nótese que para hacer referencia a los guaraníes Peramás utiliza el término Indi.

${ }^{26}$ De estas artes rústicas que aquí enumera Vanière los jesuitas les enseñaron a los indios la mayoría.

${ }^{27}$ Pero,salvo estas artes rústicas, los guaraníes eran expertos en todas las artes urbanas. Los jesuitas se ocuparon de que vinieran aquí, desde las ciudades españolas, maestros para enseñar. 
Suárez. At iam satis est de rebus guaranicis: la digressio etnográfica en el Annus Patiens de José Peramás.

propiamente dicha- con miras a aportar su propia descripción. A esta estrategia se suma la imagen que el autor forja de sí mismo (ethos) a partir de la retórica del "yo vi", lo cual le permite asumir su condición de testis y brindarle al lector la representación de la alteridad a partir de una imagen de realismo y objetividad que intenta legitimar el relato. Dicho modelo retórico se vincula estrechamente con la tendencia historiográfica americanista de producir obras en oposición a las historias conjeturales del nuevo mundo propugnadas por la Europa ilustrada ${ }^{28}$.En este sentido, pues, Peramás se vale de la digresión etnográfica no solo para ofrecer una síntesis de la sociedad guaraní sino para representar dicha sociedad a partir de su experiencia y responder a las diatribas contra la naturaleza y los pobladores americanos, sumándose de este modo al debate epistemológico en el marco de un contexto europeo adverso y controversial ${ }^{29}$.

\section{Referencias bibliográficas}

\section{Ediciones}

Furlong, G. 1952. José Manuel Peramás y su Diario del Destierro, Buenos Aires, Librería del Plata.

Perrén de Velasco, L. 2004. Diario del Destierro de J. Peramás, Córdoba, Colección Jesuitas.

Peramás, J. 1768. Jhs. Narración de lo sucedido a los Jesuitas del Paraguai desde el día de su arresto hasta la ciudad de Faenza en Italia en carta de 24 de Diciembre 1768, escrita en Turín a un Señor Abate de la ciudad de Florencia.

Peramás, J. 1768. Annus patiens siue Ephemerides quibus continetur iter annum Jesuitarum Paraquariorum Corduba Tucumaniae profectorum.

\section{Traducciones}

Patrignani, G.- Boero, G. 1859. Menologio di pie memoried' alcuni religiosi della Compagnia di Gesù, Roma, Civilta Cattolica.

Carayon, A. 1874-1886. Documents inédits concernant la Compagnie de Jésus, Paris,

Ch. Taranne Libraire.

\section{Bibliografia}

Amossy, R. 2010. La présentation de soi. Ethos et identité verbale, Paris, PUF.

\footnotetext{
${ }^{28}$ Cañizares-Esguerra (2007) define esta tendencia con el sintagma "epistemología patriótica" que en el s. XVIII puso en entredicho la capacidad de los extranjeros para comprender la historia de América y sus pueblos. "La epistemología patriótica", afirma, "fue el discurso de una clase patricia que evaluó las fuentes según la posición social de los testigos" (31).

${ }^{29}$ Creemos que Peramás se vale de la digressio para desmentir la deficiente y errónea información europea en torno del territorio americano. De hecho, en la primera digresión del Annus Patiens dedicada a la descripción de la Pampa, se propone dar cuenta, sin clasificaciones científicas, de su relación con la naturaleza sudamericana; y traducir el efecto de sorpresa o asombro frente a la novedad y la grandeza de la fauna. Cf. Suárez (2015).
} 
Arbo, D. - Laird, A. 2015. "Columbus, the Lily of Quito, and the Black Legend: the context of José Manuel Peramás' Epic on the Discovery of the New World: De invento novo orbe inducto que illuc christi sacrificio (1777)". En: Dieciocho 38.1, pp. 7-32.

Asúa, M. de. 2003. "Los jesuitas y el conocimiento de la naturaleza americana". En: Stromata 59, pp. 1-20.

Cañizares Esguerra, J. 2007. Cómo escribir la historia del Nuevo Mundo, México: FCE. Cardozo, E. 1959. Historiografía paraguaya, México, Instituto Panamericano de Geografía e Historia.

Domingues, B. 2006. “As missoes jesuíticas entre os guaranis no contexto da Ilustração". En: Historia 25(1), pp. 44-69.

Geertz, C. 1989. El antropólogo como autor, Barcelona, Paidós.

Hartog, F.2002. El espejo de Heródoto, México, FCE.

Justo, S. 2012. "Testigos directos de la naturaleza paraguaya. Novedad y tradición en las historias y crónicas jesuitas entre el Renacimiento y la Ilustración”. En: Páginas 4.7 (revista digital de la Escuela de Historia). URL: http://rephip.unr.edu.ar/ handle/2133/4568. Consultado el 20 de febrero de 2017.

Lausberg, H. 1967. Manual de Retórica Literaria, Madrid, Gredos.

Marcus, G.-Cushman, D. 1982. "Ethnogaphies as Text". En: Anual Review of Anthropology 11, pp. 25-69.

Morales, M. (ed.) 2005. A mis manos han llegado: Cartas de los PP. Generales a la antigua Provincia del Paraguay (1608-1639), Madrid, Universidad Pontificia Comillas.

Padgen, A. 1993. European Encounters with the New World. From Renaissance to Romanticism, New Haven \& London, Yale University Press.

Perelman, Ch. -Olbrechts-Tyteca, L. 1989. Tratado de la argumentación. La nueva retórica, Madrid, Gredos.

Pino Díaz, F. 2008, "La historia natural americana como campo metafórico. A propósito de la ciencia jesuita temprana en estudios recientes”. En: Dialogía, 3, pp. 213244.

Sommevogel, C. 1890-1932. Bibliothèque de la Compagnie de Jésus. Bruxelles: O. Schepens; Paris: A. Picard, 12 vol.

Suárez, M. 2015. "La historia natural en el Annus Patiens del P. Peramás: el caso de la laus animalium". En: Jornadas Interdisciplinarias sobre el s. XVIII, Facultad de Filosofía y Letras, Universidad de Buenos Aires.

Urdapilleta Muñoz, M. 2015. "La etnografía retórica en las relaciones de viaje a Indias hasta la primera mitad del siglo XVI". En: Baraibar, A.- Vinatea Recoba, M. (eds). Viajes y ciudades míticas, Pamplona, Servicios de Publicaciones de la Universidad de Navarra. 
Suárez. At iam satis est de rebus guaranicis: la digressio etnográfica en el Annus Patiens de José Peramás.

\section{IMAGEN DEL AUTÓGRAFO (ff.57-58)}

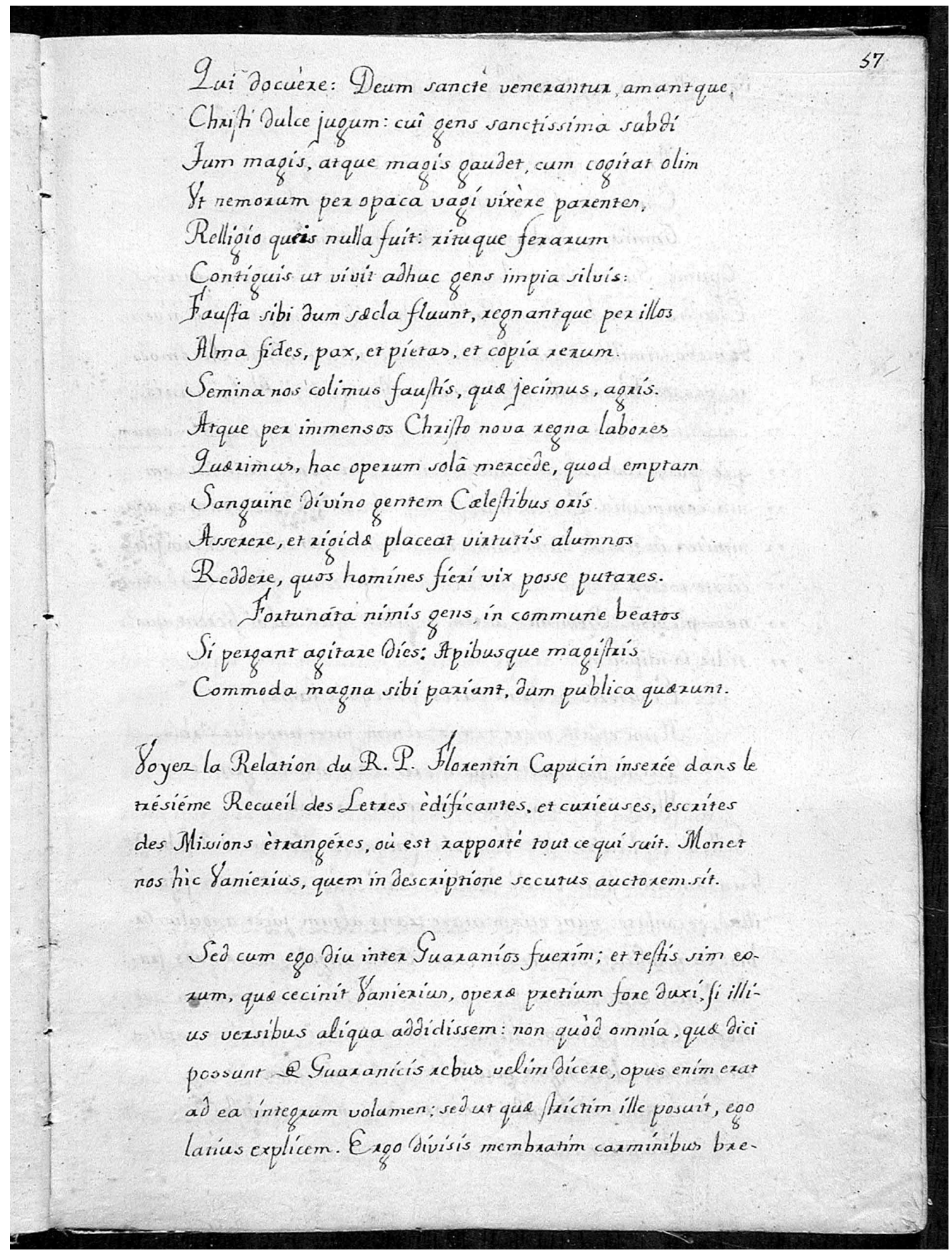


vern illozum explicationem vubjiciarn.

Annique mentem vabeat piezatís imago,

Cum sua Chrifiade sic in commune fexentes

Omnia, condebarir placíbos sine cximíne soles.

Oprime Guaranioxum laudes oxfírux Sanexíus à pximoxum Chxifianoxum laugibus. Paifina enim illi, et sanctissimo viven Gemobo simillima exat Guavanioxum vitd condinzo. Accomoda. re posses Suaraniis illud Acruum App.(c.4.)"Mlaltinudinis

" cxedentium exat cox unum, er anima una: nec quisquam eoxum,

") que possidebat, aliquid suum esse dicebat; sed éxant illi's om-

$\rightarrow$ nia communía. Etitem illuj(c.2.) Zustidie pexjuxantes una. ", nimitien in zemplo sumebant cibum cum exultazione, ez simpli-

$\rightarrow$ cirate coxfís. Collauidantes (Deum, et habentes gratíam ad'om-

, nem plebem. Dominus autem augebaz, quí salvífíczent qus-

"ridic in idipsum.

Ervetexis nevaria putes preconía fams.

Muncetiam maxe trans áltum jacer anqulus Oxbis, Quem quinsxit, Apum cxedar me nomine gentis

Jllius ingenium et vaxios celebrasse laboxes.

Sellem explicuisser hic Vaniexius (neque id poeram dedecebaz) Guaxamoxum fines vauló latius, claxiuisque: nimis enim jejunè illud, er confuse: munce etridm inaxe raans alnum jarer angulus Oxbis: cum infiniti sint teans maxe $O$ ebis anquli; intex quos fouAra, nisi expressioncs fines posuexis, Guaranican gentem quesieris. Cexie princeps Sirgilíus utrem non ita nobilem explica. xet notissima loci signa posuit. Seoxo. 4. autiollum:

- Iempus et Axcadii memoxanda inventa magifraí

Pardexe..... 